\title{
Carbon K-Edge NEXAFS and FTIR-ATR Spectroscopic Investigation of Organic Carbon Speciation in Soils
}

\author{
Dawit Solomon,* Johannes Lehmann, James Kinyangi, Biqing Liang, and Thorsten Schäfer
}

\begin{abstract}
Soil organic matter (SOM) is a fundamental component of soil and the global $C$ cycle. We used $C$ (1s) near-edge $x$-ray absorption fine structure (NEXAFS) and synchrotron-based Fourier transform infrared-attenuated total reflectance (FTIR-ATR) spectroscopy to speciate $C$ and investigate the influence of land use on the composition of SOM in the humic substances extracted from clay and silt fractions. Soil samples were collected from natural forest, tea and Cupressus plantations and cultivated fields in Ethiopia. Carbon K-edge spectra revealed multiple $C$ (1s) electron transitions in the fine structure of $C$ NEXAFS region (284-290 $\mathrm{eV}$ ) indicating the presence of aromatic$\mathrm{C}$, phenolic-C, aliphatic-C, carboxylic-C, and $\mathrm{O}$-alkyl-C in the humic substances. It also exhibited good selectivity, where specific energy regions correspond to $\mathrm{C}$ in discrete functional groups. However, regions of slight overlap between $1 \mathrm{~s}-3 \mathrm{p} / \mathrm{\sigma}^{*}$ transition of aliphatic-C and $1 \mathrm{~s}-\pi^{*}$ transition of carboxylic-C may not be excluded. Fourier transform infrared-attenuated total reflectance spectroscopy showed larger proportions of aromatic-C $(25.5 \%, 21.9 \%)$ and asymmetric and symmetric aliphatic-C $(19.7 \%, 15.2 \%)$ groups in the silt than in clay, respectively. However, smaller proportion of polysaccharides $(19.3 \%$, $11.5 \%$ ) was obtained from the silt compared with clay. The proportions of phenols $(20.7 \%, 20.4 \%)$, aliphatic deformation of $\mathrm{CH}_{2}$ or $\mathrm{CH}_{3}$ $(13.1 \%, 14.5 \%)$, and carboxylic $(9.8 \%, 8.3 \%)$ groups were of similar magnitude in both fractions. The proportion of polysaccharides decreased in the order: natural forests $>$ plantations $>$ cultivated fields, while recalcitrant aromatic- $\mathrm{C}$ increased in the order: natural forest $<$ plantation $<$ cultivation. Therefore, C (1s) NEXAFS and synchrotronbased FTIR-ATR spectroscopy are powerful, nondestructive techniques that can potentially be used not only to identify and fingerprint complex structural characteristics of organic $\mathbf{C}$ macromolecules but also to investigate the impact of long-term anthropogenic management on the composition and biogeochemical cycling of organic $\mathrm{C}$ in terrestrial ecosystems.
\end{abstract}

$T$ he Intergovernmental Panel on Climate Change (IPCC) recently confirmed that anthropogenic greenhouse effect is a reality (IPCC, 2001). Analysis of landuse changes through forest clearing to agricultural land has shown that global terrestrial ecosystems are net sources of $\mathrm{C}$ emission $\left(1.7 \pm 0.8 \mathrm{Pg} \mathrm{C} \mathrm{yr}^{-1}\right)$ to the atmosphere (IPCC, 2001). Soils contain the principal organic C pool (1220-1550 Pg) of the terrestrial C reserves (2300 $\mathrm{Pg})(\mathrm{Lal}, 2001)$ and its transformation is an important element in the global $\mathrm{C}$ cycle. Land-use changes affect not only the amount but also the composition of SOM through their influence on the decomposition and humi-

D. Solomon, J. Lehmann, J. Kinyangi, and B. Liang, Cornell University, Dep. of Crop and Soil Sciences, Bradfield and Emerson Hall, Ithaca, NY 14853; T. Schäfer, Forschungszentrum Karlsruhe, Institute für Nukleare Entsorgung (INE), P.O. Box 3640, D-76021 Karlsruhe, Germany. Received 19 May 2004. *Corresponding author (ds278@ cornell.edu).

Published in Soil Sci. Soc. Am. J. 69:107-119 (2005).

(c) Soil Science Society of America

677 S. Segoe Rd., Madison, WI 53711 USA fication processes (Solomon et al., 2002). Soil organic matter is a complex material consisting of plant biopolymers (e.g., polysaccharides, lignin, proteins, and cuticular materials), animal and microbial residues and humic substances (Chefetz et al., 2002). The amount, chemical composition, and polyelectrolytic characteristics of the resulting organic $\mathrm{C}$, however, may vary considerably depending on the climate, origin, and age of the organic material (Chen et al., 2002). It is these changes and heterogeneities that have made the structural and functional characterization of soil organic $\mathrm{C}$ extremely challenging.

Several approaches using modern and fairly effective analytical techniques are available for the characterization of organic matter and humic substances associated with bulk soils and size separates. These techniques involve the use of (i) chemolytic (Kögel-Knabner, 1995; Zhang and Amelung, 1996; Solomon et al., 2002), (ii) pyrolysis (Saiz-Jimenez, 1994; Leinweber and Schulten, 1998), (iii) thermochemolysis (del Rio et al., 1998; Chefetz et al., 2002), (iv) compound-specific stable isotope and radiocarbon analysis (Eglinton et al., 1996; Macko et al., 1998), and (v) spectroscopic techniques (Gressel et al., 1995; Kögel-Knabner, 1997; Solomon et al., 2002; Pérez et al., 2004).

Although significant progress has been made in SOM investigations using these analytical techniques, advances in SOM characterization could further benefit from the progress made in nondestructive microscopic and microscale $\mathrm{x}$-ray spectroscopy techniques such as scanning electron microscopy (SEM), energy dispersive $\mathrm{x}$-ray (EDX) analysis, and x-ray photoelectron spectroscopy (XPS) (McKeague and Wang, 1980; McHardy and Robertson, 1983; Yuan et al., 1998) to get information about the chemical composition, microheterogenity, and physical allocation of organic and mineral materials in soils (Kögel-Knabner, 2000; Scheinost et al., 2001). A more recent addition to the ensemble of microscale physical and chemical characterization techniques is synchrotron-based scanning transmission $\mathrm{x}$-ray microscopy (STXM), a powerful method created through advances in X-ray microfocusing techniques and access to a high flux source of soft x-ray photons generated by synchrotron light sources. Synchrotron radiation is a light emitted by highly relativistic electrons as they transit the magnetic fields used to guide them along a closed orbit (Lobo et al., 2002). The emitted radiation extends

Abbreviations: Ac, acetate; CEC, cation exchange capacity; FTIRATR, Fourier transform infrared spectroscopy-attenuated total reflectance, G, Gaussian peaks; HUMO, highest unoccupied molecular orbital; IPCC, Intergovernmental Panel on Climate Change; LUMO, lowest unoccupied molecular orbital; NEXAFS, near edge x-ray absorption fine structure; NMR, nuclear magnetic resonance; SOM, soil organic matter; STXM, scanning transmission $\mathrm{x}$-ray microscopy. 
from microwaves to the hard x-ray region. By connecting a tunable monochromator to the STMX, NEXAFS spectra close to the $\mathrm{C} \mathrm{K}$-edge, at the first $30 \mathrm{eV}$ above the actual electron binding energy for $\mathrm{C}(284 \mathrm{eV})$ (Stöhr, 1992; Gutiérrez-Sosa et al., 1999; Rothe et al., 2000) can be collected. This region usually shows the largest variation in the $\mathrm{x}$-ray absorption coefficient and is often dominated by intense narrow resonances (Stöhr, 1992). Carbon NEXAFS features arise from electronic transitions of an inner-shell electron to unfilled molecular orbitals or conduction bands. As the incident photon energy increases throughout an absorption edge, first structures associated with excitation to the lowest unoccupied molecular orbital (LUMO), which are $\pi^{*}$ antibonding orbitals and mixed Rydberg/valence states for unsaturated molecules (double or triple covalent bonds) will appear. As the incident photon energy increases, the ionization threshold will be exceeded whereby the core electron may be completely removed from the influence of the core hole; that is, the electron will be promoted to continuum. Above the ionization threshold of C (approximately $290 \mathrm{eV}$ ) but still within the NEXAFS region, structures associated with higher energy unoccupied molecular orbitals (HUMO), typically of $\sigma^{*}$ character associated with saturated (single) covalent bonds, and direct inner-shell ionization are anticipated (Stöhr, 1992; Cody and Botto, 1995; Scheinost et al., 2001). The unoccupied electronic structure and thus the inner-shell excited states are determined by the geometric and electronic (bonding) structure of the sample. These features make NEXAFS element specific and also very sensitive to the bonding environment thus making it a powerful tool to identify and fingerprint the chemical structure of organic $\mathrm{C}$ from the fine scale details of the absorption spectrum that occur at its edge. Carbon (1s) NEXAFS has been effectively employed in the past to study coal (Cody and Botto, 1995; Cody et al., 1995), humic substances (Rothe et al., 2000; Schmidt et al., 2000a) and biopolymers like amino acids and peptides (Boese et al., 1997). In these studies, the functional group chemistry of samples with unknown composition has been inferred from reference spectra in a qualitative way by comparing band height and shapes. More recently, however, Scheinost et al. (2001), Jokic et al. (2003), and Schäfer et al. (2003) have employed a semi-quantitative approach to interpret NEXAFS spectra in non-living organic matter in soils.

Numerous studies conducted using conventional source of infrared light in the past indicated that FTIR spectroscopy could provide an insight into structural characteristics of complex organic macromolecules such as humic substances (Schnitzer and Khan, 1972; Stevenson and Goh, 1971; Inbar et al., 1989; Haberhauer et al., 1998). The FTIR spectra of such macromolecules contain a variety of bands that are diagnostic and could serve as a valuable tool to characterize the principal classes of chemical groups of which SOM is comprised. In the present investigation, we employed synchrotron-based FTIR-ATR technique. Combining FTIR with synchrotron infrared light, which is up to 1000 times brighter than a conventional infrared source, may help us to study the chemistry of samples that are smaller and/or more dilute in concentration in a nondestructive manner (Martin and McKinney, 1998). The use of ATR may provide an extra advantage by eliminating some of the problems associated with transmission infrared spectroscopy such as path length, concentration, and interference of water bands in the humic substance spectra due to the hygroscopic nature of $\mathrm{KBr}$ used for the preparation of conventional FTIR pellets (Tanaka et al., 2001).

The objectives of the present study were, therefore, (i) to assess the potentials of C (1s) NEXAFS and synchrotron-based FTIR-ATR spectroscopy to qualitatively and quantitatively characterize the functional groups of organic $\mathrm{C}$ and their distribution in organomineral particles of soils and (ii) to investigate the usefulness of these techniques to evaluate the impact of deforestation and land-use changes on the composition of organic C in size separates. The results from C (1s) NEXAFS and FTIR-ATR spectroscopy were related to the organic $\mathrm{C}$ functional groups determined using ${ }^{13} \mathrm{C}$ nuclear magnetic resonance (NMR) spectroscopy (Solomon et al., 2002).

\section{MATERIALS AND METHODS Site Description and Sample Preparation}

The present study was conducted on soil samples collected from the southwestern highlands (Wushwush) and the southeastern Rift Valley escarpment (Munesa) of Ethiopia. Wushwush is located at $7^{\circ} 19^{\prime} \mathrm{N}$ lat. and $36^{\circ} 07^{\prime} \mathrm{E}$ long. The altitude of the area is $1900 \mathrm{~m}$ above sea level. Mean annual temperature is $18^{\circ} \mathrm{C}$ with an average annual precipitation of $1800 \mathrm{~mm}$. The soils of the area have clayey texture, dark reddish brown color, and are classified as Plinthaquic Paleudalfs (Soil Survey Staff, 1999). The Munesa site is located at $7^{\circ} 35^{\prime} \mathrm{N}$ lat. and $38^{\circ} 45^{\prime} \mathrm{E}$ long. Mean annual temperature is $19^{\circ} \mathrm{C}$ with annual precipitation of $1250 \mathrm{~mm}$. The soils at Munesa are well-drained, clayey textured and very dark reddish brown in color. They are classified as Typic Palehumults (Soil Survey Staff, 1999).

The land-use practices studied at the Wushwush site include natural forest, tea plantation (Camellia sinensis O. Kuntz) ( $35 \mathrm{yr}$ old) and fields cultivated for $25 \mathrm{yr}$, while at the Munesa site Podocarpus dominated natural forest, Cupressus plantation (Cupressus lusitanica Mill.) (25 yr old) and fields cultivated for $30 \mathrm{yr}$ were investigated. In the cultivated fields of both sites, maize (Zea mays L.) was grown without fertilizer inputs. However, during the intermittent dry periods, sorghum (Sorghum bicolor L. Moench) was grown at Munesa. The plowing depth both at the Wushwush and Munesa sites varies from 10 to $12 \mathrm{~cm}$. Crop residues that remain on the fields are normally collected and used as animal feed at both sites. Detailed descriptions of the vegetation and other site characteristics of the study area were provided in Solomon et al. (2002). We selected three representative fields from each landuse system and collected nine subsamples in a radial sampling scheme (Wilding, 1985) using a core sampler $\left(200 \mathrm{~cm}^{3}\right.$ core volume) from the upper $10 \mathrm{~cm}$ of each field. A composite sample was then prepared from the subsamples. The samples were then air-dried and sieved $(<2 \mathrm{~mm})$ before fractionation and chemical analysis. 


\section{Physical Fractionation of Particle-Size Separates}

After removing visible root remnants, $30 \mathrm{~g}$ of soil was ultrasonically treated with an energy input of $60 \mathrm{~J} \mathrm{~mL}^{-1}$ using a probe type sonicator (Branson Sonifier W-450, Schwäbisch Gmünd, Germany) in a soil/water ratio of 1:5 (w/v). The coarse sand-size separates $(250-2000 \mu \mathrm{m})$ were isolated by wet sieving. To completely disperse the remaining material in the $<250-\mu \mathrm{m}$ suspension, ultrasound was again applied with an energy input of $440 \mathrm{~J} \mathrm{~mL}^{-1}$ in a soil/water ratio of 1:10 (w/v). The clay-size separates $(<2 \mu \mathrm{m})$ were separated from the silt $(2-20 \mu \mathrm{m})$ and fine sand $(20-250 \mu \mathrm{m})$ size separates by repeated centrifugation. The silt size separates were separated from the fine sand-size separates by wet sieving. Coarse and fine sand separates were combined and finally all size separates were dried at $40^{\circ} \mathrm{C}$ before grinding them for chemical analysis. The detailed procedure of isolation of the different size separates is described elsewhere (Solomon et al., 2002).

\section{Chemical Analysis}

Carbon and $\mathrm{N}$ contents of the clay and silt fractions were analyzed by dry combustion using a $\mathrm{C} / \mathrm{H} / \mathrm{N} / \mathrm{S}$-analyzer (Elementar Vario EL; Elementar Analysensysteme GmbH, Hanau, Germany). The $\mathrm{pH}-\mathrm{KCl}$ was determined in 1:2.5 (w/v) suspensions. Cation exchange capacity (CEC) was determined with $1 \mathrm{MNH}_{4} \mathrm{OAc}$ (ammonium acetate) $(\mathrm{pH}=7.0)$ according to Avery and Bascomb (1974). Dithionite-citrate-bicarbonateextractable $\mathrm{Al}$ and $\mathrm{Fe}\left(\mathrm{Al}_{\mathrm{d}}, \mathrm{Fe}_{\mathrm{d}}\right)$ as well as oxalate-extractable $\mathrm{Al}$ and $\mathrm{Fe}\left(\mathrm{Al}_{0}, \mathrm{Fe}_{\mathrm{o}}\right)$ were determined using atomic absorption spectrometer (Varian AAS-400; Varian Techtron, Victoria, Australia) according to Mehra and Jackson (1960) and Blume and Schwertmann (1969). Selected soil physical and chemical characteristics are shown in Table 1.

\section{Humic Substance Extraction}

The extraction procedure of humic substances for NEXAFS and FTIR-ATR spectroscopy followed the outline in Solomon et al. (2003). The humic substances from the clay and silt fractions were extracted three times with a $0.1 \mathrm{M} \mathrm{NaOH}$ and $0.4 M \mathrm{NaF}$ mixture at 1:5 (w/v) ratio and the combined extracts were filtered through a $0.2-\mu \mathrm{m}$ membrane filter (Gelman Supor; Pall Gelman Laboratory, Ann Arbor, MI) under pressure. This procedure was repeated using the same membrane filter, where the partial plugging of the filter helps remove fine clay. Finally the extracts were dialyzed (Spectra/Por Membrane, MWCO, 12 000-14 000 Da; Spectrum Laboratories, Gardena, $\mathrm{CA}$ ) and freeze-dried. The $\mathrm{NaOH}-\mathrm{NaF}$ solution extracted from 52 to $64 \%$ of the total SOM from the particle-size separates of the soils under investigation.

\section{Near Edge X-Ray Absorption Fine Structure Spectroscopy}

Characterization of the humic substances extracted from the clay and the silt size separates using C (1s) NEXAFS was done at the X-1A1 beamline of the National Synchrotron Light Source (NSLS), Brookhaven National Laboratory using the STXM endstation. The essential components of the STMX used in the present experiment were a tunable undulator, which is inserted in the $2.8 \mathrm{GeV}$ electron storage ring generating a high flux photons at $10^{6}$ spatially coherent photons $\mathrm{s}^{-1}$ in the soft $\mathrm{x}$-ray region, a spherical grating monochromator with maximum spectra resolving power of 5000 lines $\mathrm{mm}^{-1}$, a $160-\mu \mathrm{m}$ Fresnel zone plate with a normal spatial resolution of $45 \mathrm{~nm}$ and a proportional counter to detect the transmitted photons (Neuhäusler et al., 1999; Scheinost et al., 2001). The beamline slit width was set up at 40 um for the entrance slit, $25 \mu \mathrm{m}$ for the vertical exit slit and $25 \mu \mathrm{m}$ for the horizontal exit slit. The monochromator was calibrated using the absorption band of $\mathrm{CO}_{2}$.

Films of humic substance samples were prepared from the aqueous suspension obtained by dispersing them in Millipore water using ultrasound bath for sample uniformity. We transferred 3- $\mu \mathrm{L}$ droplets of the aqueous suspension to $100-\mathrm{nm}$ thick $\mathrm{Si}_{3} \mathrm{~N}_{4}$ windows (Silson Ltd, Northampton, England) and dried the suspension at $35^{\circ} \mathrm{C}$. After high-resolution micrographs of the samples were taken using the STXM to locate the area of uniform thickness, the illuminated spot on the samples were then increased to $10 \mu \mathrm{m}$ by defocusing the zoneplate. Spectra from the samples (I) were collected from three different spots through the films and $\mathrm{SiN}_{3}$ windows by moving the grating from 280 to $310 \mathrm{eV}$ on a single spot with $120 \mathrm{~ms}$ dwell times in steps of $0.1 \mathrm{eV}$. Before each sample scan, background spectra $\left(\mathrm{I}_{0}\right)$ were collected in triplicates (as mentioned above) through the sample free region of the same $\mathrm{Si}_{3} \mathrm{~N}_{4}$ windows and averaged.

The spectra were deconvoluted using arctangent function (AT) for the ionization step at $290 \mathrm{eV}$ with full-width at halfmaximum (FWHM) of $0.4 \mathrm{eV}$ to generate a continuum of spectrum up to $294 \mathrm{eV}$. The FWHM of the Gaussian peaks (G) was set at $0.4 \mathrm{eV}$ and six Gaussian functions representing the main $1 \mathrm{~s}-\pi^{*}$ transitions at $284.3(\mathrm{G} 1), 285.0(\mathrm{G} 2), 286.5$ (G3), 287.3 (G4), 288.4 (G5), and 289.3 (G6) eV and two second higher $\left(1 \mathrm{~s}-2 \pi^{*}\right)$ transitions at $(289.1$ and $289.7 \mathrm{eV}$, data not shown) were resolved (Cody et al., 1998; Scheinost et al., 2001; Schäfer et al., 2003). Moreover, two Gaussian peaks for $\sigma^{*}$ transitions $\left(\sigma^{1}\right.$ and $\left.\sigma^{2}\right)$ were simulated with FWHM of $<1$ and $<2 \mathrm{eV}$ using WinXAS version 3.0 for windows (WinXAS Software, Hamburg, Germany). The spectra were pre-edge normalized using WinXAS version 3.1 to

Table 1. Some physical and chemical properties of surface soils $(0$ to $10 \mathrm{~cm})$ collected from the sub-humid Ethiopian highlands.

\begin{tabular}{|c|c|c|c|c|c|c|c|c|c|c|c|c|}
\hline Land use & Sand & Silt & Clay & pH & SOC $\dagger$ & $\mathbf{N}$ & $\mathbf{C} / \mathbf{N}$ & CEC & $\mathbf{F e}_{\mathrm{d}} \ddagger$ & $\mathbf{F e}_{0} \S$ & $\mathbf{A l}_{\mathrm{d}}+$ & $\mathbf{A l}_{0} \S$ \\
\hline & $\longrightarrow$ & $\mathbf{k g}^{-1}$ & - & KCl & \multicolumn{3}{|c|}{$-\mathbf{g ~ k g}^{-1}$ soil - } & $\underset{\text { soil }}{\mathrm{cmol} \mathrm{kg}^{-1}}$ & \multicolumn{4}{|c|}{$\longrightarrow \mathrm{g} \mathrm{kg}^{-1}$} \\
\hline \multicolumn{13}{|c|}{$\underline{\text { Wushwush }}$} \\
\hline Natural forest & 103 & 327 & 570 & 5.5 & 82 & 7.7 & 10.8 & 37.0 & 6.7 & 0.60 & 0.96 & 0.25 \\
\hline Tea plantation & 102 & 330 & 568 & 4.5 & 42 & 4.0 & 10.4 & 24.7 & 6.5 & 0.70 & 0.97 & 0.32 \\
\hline Cultivation & 70 & 337 & 593 & 4.7 & 38 & 3.7 & 10.2 & 26.4 & 5.8 & 0.83 & 0.77 & 0.30 \\
\hline \multicolumn{13}{|c|}{$\underline{\text { Munesa }}$} \\
\hline Natural forest & 130 & 347 & 523 & 6.8 & 98 & 7.9 & 12.6 & 52.2 & 2.5 & 0.30 & 0.38 & 0.15 \\
\hline Cupressus plantation & 231 & 326 & 443 & 6.6 & 71 & 7.1 & 10.0 & 40.4 & 2.5 & 0.36 & 0.32 & 0.18 \\
\hline $\begin{array}{l}\text { Cultivation } \\
\text { (1) }\end{array}$ & 229 & 285 & 486 & 4.5 & 38 & 3.3 & 11.8 & 26.5 & 3.4 & 0.71 & 0.40 & 0.21 \\
\hline
\end{tabular}

$\dagger$ SOC, soil organic carbon.

$+\mathrm{Fe}_{\mathrm{d}}$ and $\mathrm{Al}_{\mathrm{d}}$, dithionite-citrate-bicarbonate extractable $\mathrm{Fe}$ and $\mathrm{Al}$.

$\S \mathrm{Fe}_{\mathrm{o}}$ and $\mathrm{Al}_{0}$, oxalate extractable $\mathrm{Fe}$ and $\mathrm{Al}$. 
avoid spectral dependence on the total $\mathrm{C}$ content; therefore, spectral properties are indicative of changes in $\mathrm{C}$ chemistry (Jablonski et al., 2003). Since the fine structure in the C NEXAFS region above $290 \mathrm{eV}$ transitions tends to be very broad and overlap (Cody et al., 1998; Schäfer et al., 2003), only main $1 \mathrm{~s}-\pi^{*}$ transitions were used for subsequent quantification and interpretation of the C (1s) NEXAFS results in the present investigation.

\section{Fourier Transform Infrared Spectroscopy}

The synchrotron-based FTIR-ATR experiment was performed on the U10B beamline at the National Synchrotron Light Source (NSLS), Brookhaven National Laboratory. The beamline is equipped with a Spectra Tech Continuum IR microscope fitted with $32 \mathrm{x}$ transmission/reflection and FTIR step-scan spectrophotometer (Nicolet Magna 860, Thermo Nicolet Corp., Madison, WI) with a $\mathrm{KBr}$ beam splitter and mercury-cadmium-telluride (MCT) detector with 500- to 7000$\mathrm{cm}^{-1}$ frequency range and $1.0 \mathrm{~cm}^{-1}$ spectral resolution.

Films of humic substance samples extracted from the clay and silt separates were prepared from the aqueous suspension obtained in similar manner as the ones for NEXAFS spectroscopy. We transferred $10-\mu \mathrm{L}$ droplets of the aqueous suspension on infrared (IR) glass slides (Silon Ltd, Northampton, England) and the suspension was dried at $35^{\circ} \mathrm{C}$ in a vacuum oven. Spectra from the samples were recorded for IR measurements with a $10 \times 10 \mu \mathrm{m}^{2}$ aperture size from 4000 to $650 \mathrm{~cm}^{-1}$ with a resolution of $4 \mathrm{~cm}^{-1}$. Each spectrum was composed of 256 scans co-added before Fourier transform processing. After a background of the IR glass was subtracted, we used OMNIC version 6.1 for windows (Thermo Nicolete Corp. Madison, WI) on the reduced portions of the spectra $\left(4000-800 \mathrm{~cm}^{-1}\right)$ to automatically correct the baseline, normalize, identify the peaks, and calculate the intensities of the spectra.

\section{Nuclear Magnetic Resonance Spectroscopy}

Liquid-state ${ }^{13} \mathrm{C}$ NMR spectra from the humic substances were recorded on a Bruker Avance DRX 500 NMR spectrometer (Bruker BioSpin GmbH, Rheinstetten, Germany). About $150 \mathrm{mg}$ of the freeze-dried material was dissolved in $3 \mathrm{~mL}$ of $0.5 M$ sodium deuteroxide (NaOD) in a $10-\mathrm{mm}$ NMR tube. Conditions for ${ }^{13} \mathrm{C}$ NMR were: spectrometer frequency, 125.8 $\mathrm{MHz}$; inverse-gated decoupling; acquisition time, $0.33 \mathrm{~s}$; delay time, $1.67 \mathrm{~s}$; line-broadening factor, $100 \mathrm{~Hz}$. Chemical shifts were recorded in ppm relative to the resonance of an external standard of TSP [3-(trimethylsilyl) propionic acid]. The signal areas were calculated by electronic integration (Solomon et al., 2002).

\section{Statistics}

Correlation coefficients showing the relationship between the organic $\mathrm{C}$ functional groups of humic substances identified by $\mathrm{C}(1 \mathrm{~s}) \mathrm{NEXAFS}$ and ${ }^{13} \mathrm{C}$ NMR chemical shifts were run using the software package SIGMA Plot Version 6.10 for windows (SPSS Inc., Chicago, IL).

\section{RESULTS AND DISCUSSION Speciation of Organic C Using C K-Edge NEXAFS Spectroscopy}

The deconvoluted typical C (1s) NEXAFS spectra showing the main $1 \mathrm{~s}-\pi^{*}$ transitions, the two $\sigma^{*}$ transitions and the arctangent step function for humic substances extracted from the clay $(<2 \mu \mathrm{m})$ fraction is

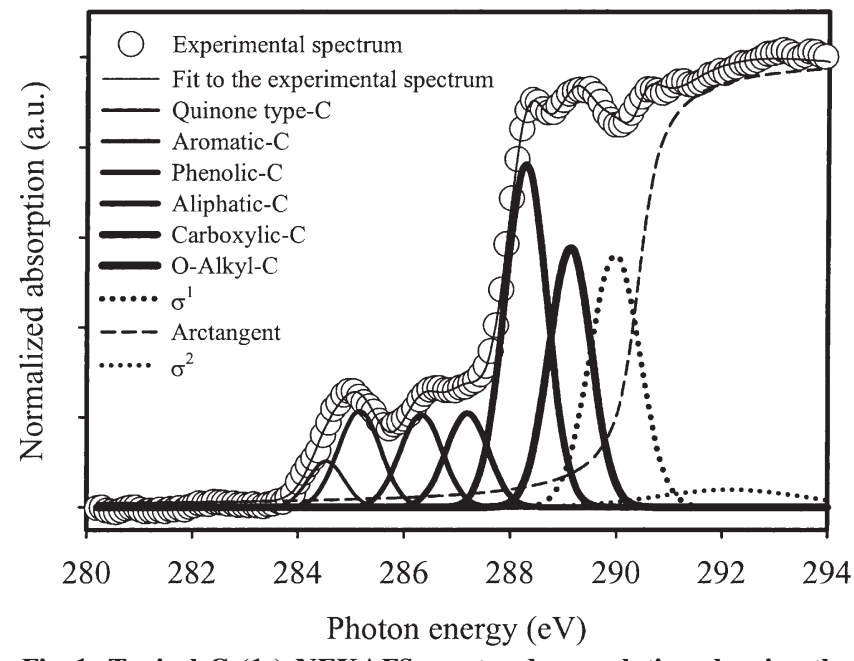

Fig. 1. Typical C (1s) NEXAFS spectra deconvolution showing the main $1 s-\pi *$ transitions, the two $\sigma^{*}$ transitions and the arctangent step function (from left to right) from humic substances extracted from clay fraction $(<2 \mu \mathrm{m})$ of a soil from Wushwush, Ethiopia. $1 s-2 \pi *$-transitions were not shown.

shown in Fig. 1. The spectra revealed multiple peaks in the fine structure of the C NEXAFS region (284-290 $\mathrm{eV}$ ) indicating the presence of various $\mathrm{C}$ functional groups in the humic substances extracted from size separates of the soils under investigation. According to Fig. 1, the C 1s- $\pi *$ transition near $284.3 \mathrm{eV}$ (G1) correspond to quinone type-C such as benzoquinone and to protonated and alkylated aromatic-C (Cody et al., 1998; Schäfer et al., 2003). The resonance near $285.0 \mathrm{eV}$ (G2) represents molecular orbital of aromatic- $\mathrm{C}$ (protonated and alkylated to carbonyl-substituted aromatic-C) and possibly olefinic-C (Cody et al., 1998; Boyce et al., 2002; Jokic et al., 2003; Schäfer et al., 2003). The sum of these two organic $\mathrm{C}$ functional groups was used in subsequent discussions throughout this paper to represent aromatic-C. The absorption band near $286.5 \mathrm{eV}$ (G3) is associated with phenolic-C including O-substituted arylC, which is indicative of lignin (Scheinost et al., 2001; Boyce et al., 2002; Schäfer et al., 2003). The 1s-3p/ $\sigma^{*}$ transition near $287.3 \mathrm{eV}(\mathrm{G} 4)$ was due to aliphatic-C, whereas the strong absorption band near $288.4 \mathrm{eV}$ (G5) was assigned to a $1 \mathrm{~s}-\pi^{*}$ transition of carboxylic-C (Cody et al., 1998; Boyce et al., 2002; Jokic et al., 2003; Schäfer et al., 2003). This is in accordance with the fact that $C$ is electron deficient in the $\mathrm{C}=\mathrm{O}$ bonding. Consequently, due to the electron withdrawing nature of $\mathrm{O}$ in the $\mathrm{C}=\mathrm{O}$ bonding, the corresponding 1 s transition appears at energies approximately $3 \mathrm{eV}$ above the $\mathrm{C}=\mathrm{C}$ transition (Cody et al., 1998; Rothe et al., 2000). The sharp absorption band near $289.3 \mathrm{eV}$ (G6) corresponds to the $1 \mathrm{~s}-\pi^{*}$ of O-alkyl-C group representing mainly polysaccharides as well as smaller proportions of alcohol and ether $\mathrm{C}$ (Boyce et al., 2002; Scheinost et al., 2001). These results indicate that for the most part, C K-edge NEXAFS spectra obtained from the humic substances exhibited good selectivity, where specific energy regions tend to correspond to the $\mathrm{C}$ in discrete organic functional groups obtained from literature (Cody et al., 1998; Scheinost et al., 2001; Schäfer et al., 2003). However, regions of 

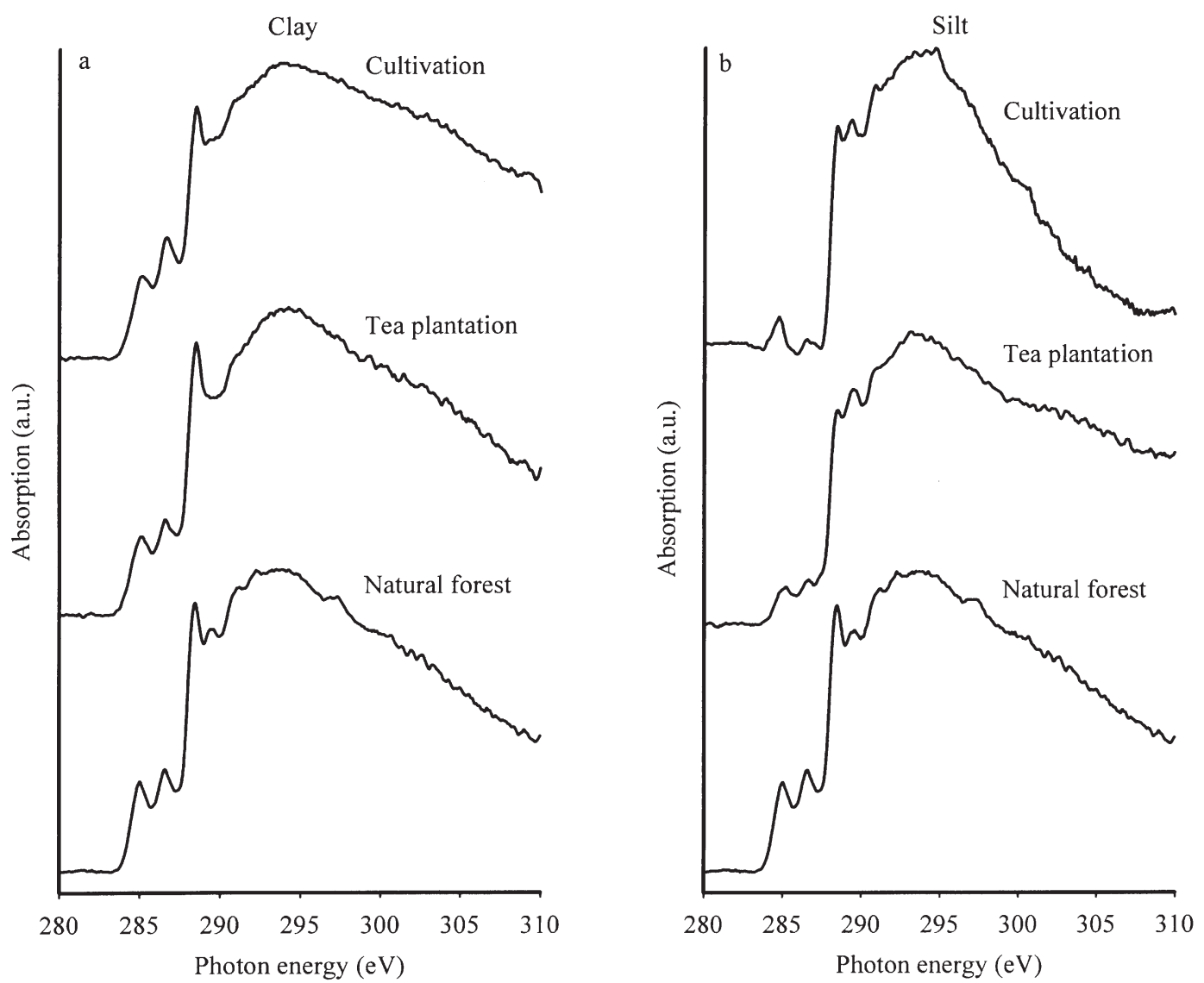

Fig. 2. Carbon (1s) NEXAFS spectra for humic substances extracted from the clay $(<2 \mu \mathrm{m})$ and silt $(2-20 \mu \mathrm{m})$ fractions of soils from Wushwush, Ethiopia.

slight overlap between the bands associated especially with $1 \mathrm{~s}-3 \mathrm{p} / \mathrm{\sigma}^{*}$ transitions of aliphatic-C near $287.3 \mathrm{eV}$ and $1 \mathrm{~s}-\pi^{*}$ transitions carboxylic-C near $288.4 \mathrm{eV}$ may not be excluded (Fig. 1). The existence of regions of overlap in C K-edge NEXAFS near 287 and $288 \mathrm{eV}$ have been also reported in the past by Cody et al. (1998).

The C (1s) NEXAFS spectra and the relative proportions of different $\mathrm{C}$ functional groups in the humic substances extracted from clay and silt fractions of the Wushwush and Munesa sites are shown in Fig. 2 and 3 and in Table 2 and 3 , respectively. The C (1s) NEXAFS spectra of the humic substances extracted from clay fraction (Fig. 2a and Fig. 3a) indicate that this size separate was dominated by strong $\mathrm{C} 1 \mathrm{~s}-\pi^{*}$ transition of carboxylic-C. This organic $\mathrm{C}$ functional group represented on average about $36.5 \%$ of the total organic C identified by $\mathrm{C}$ K-edge NEXAFS spectroscopy. The C $1 \mathrm{~s}-\pi^{*}$ transition of $\mathrm{O}$-alkyl-C is the second dominant organic $\mathrm{C}$ moiety accounting on average for $23.8 \%$ of the total organic $\mathrm{C}$, while almost similar proportions of phenolic-C (14.6\%) and aromatic-C (14.1\%) were found in the clay fraction. The $\mathrm{C} 1 \mathrm{~s}-3 \mathrm{p} / \sigma^{*}$ transition of aliphatic-C represented on average only $11.0 \%$ of the total organic $\mathrm{C}$ isolated by C NEXAFS spectroscopy from humic substances extracted from clay fraction of the soils under investigation (Table 2 and 3). Deconvolution of spectra from the silt fraction shows that the C $1 \mathrm{~s}-\pi^{*}$ transition of carboxylic-C comprises on average $41.0 \%$ of the total organic $\mathrm{C}$ in the humic substances associated with silt fraction. The $\mathrm{C} 1 \mathrm{~s}-\pi^{*}$ transition of O-alkyl-C located near $289.3 \mathrm{eV}$ represented on average $36.8 \%$, while the primary peaks around 284.3 and $285.0 \mathrm{eV}$, which correspond to excitations of aromatic- $\mathrm{C}$ comprised $11.0 \%$ of the organic $\mathrm{C}$ identified by $\mathrm{C} \mathrm{K}$-edge NEXAFS spectroscopy from the silt fraction. The phenolic-C and $1 \mathrm{~s}-\pi^{*}$ transition of aliphatic-C accounted on average for 6.3 and $4.9 \%$ of the organic C, respectively (Table 2 and 3 ). The results from both size fractions thus indicate that carboxylic- $\mathrm{C}$ and $\mathrm{O}$-alkyl-C groups were the dominant forms of organic $\mathrm{C}$, followed by moderate amounts of aromatic- $\mathrm{C}$ and phenolic- $\mathrm{C}$ groups. The aliphatic- $\mathrm{C}$ forms contributed only to a small portion of the total SOM associated with humic substances extracted from both the clay and silt fractions. These results are in line with the C (1s) NEXAFS results of Rothe et al. (2000) and Schäfer et al. (2003), where large amounts of carboxyl-C and O-alkyl-C moieties were reported in humic substances. They are also partially consistent with the results of Jokic et al. (2003), where large proportions of O-alkyl-C and carboxylic-C followed by aromatic-C and alkyl-C have been observed by $\mathrm{C}$ K-edge studies from the surface layers (approximately $10 \mathrm{~nm}$ ) of wetland soils using total electron yield (TEY) mode. Jokic et al. (2003), however, reported an increase in the proportion of aliphatic-C compared with both carboxylic- $\mathrm{C}$ and aromatic- $\mathrm{C}$ from the same soils 

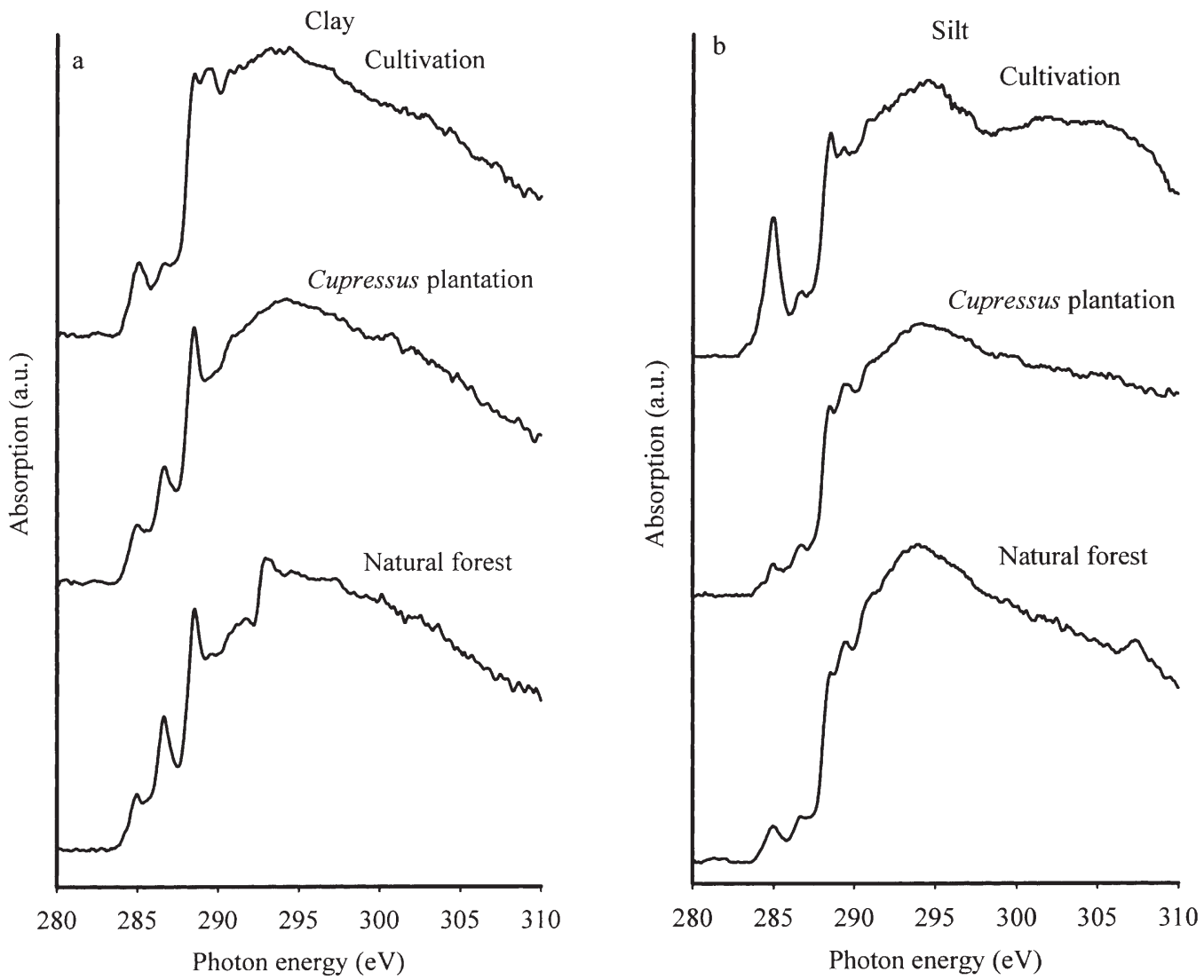

Fig. 3. Carbon (1s) NEXAFS spectra for humic substances extracted from the clay $(<2 \mu \mathrm{m})$ and silt $(2-20 \mu \mathrm{m})$ fractions of soils from Munesa, Ethiopia.

using fluorescence yield (FY) that probes deeper (approximately $100 \mathrm{~nm}$ ) in to the sample. Examination of the NEXAFS spectral features revealed also small but consistent differences in the peak intensities of the organic $\mathrm{C}$ functional groups identified from the humic substances extracted from clay and silt fractions. The most prominent changes in the $\mathrm{C}$ K-edge NEXAFS spectra were indicated by the $\mathrm{C} 1 \mathrm{~s}-\pi^{*}$ transition intensities between 284.3 and $288.4 \mathrm{eV}$ (Fig. 2 and 3). The intensity of $\mathrm{C} 1 \mathrm{~s}-\pi^{*}$ transitions of $\mathrm{C}$ functional groups between these absorption bands were generally larger and more well resolved in the clay fraction compared with the corresponding silt fraction. These features may reflect lower proportion of these organic $\mathrm{C}$ moieties in the SOM associated with the silt fraction.

Comparisons of the results from C K-edge NEXAFS spectroscopy indicates that regardless of the large losses of SOC in the clay (from 22 to $44 \%$ ) and silt (from 41 to $78 \%$ ) following management changes (Solomon et al., 2002), the NEXAFS spectral features did not reveal clear and consistent differences in relative abundance of the various organic $\mathrm{C}$ functional forms in the humic substances extracted from the size separates of soils among the contrasting land-use systems (Fig. 2 and 3 and Tables 2 and 3). These results are in accordance with previous studies (Skjemstad et al., 1986; Capriel et al., 1992; Guggenberger and Zech, 1999; Solomon et al., 2002) where, despite large losses in SOM contents following land-use changes, ${ }^{13} \mathrm{C}$ NMR spectroscopy failed to show significant differences in the structural makeup of SOM.

To evaluate the deconvolution procedure used for

Table 2. Relative proportions of organic C functional groups identified by C (1s) NEXAFS spectroscopy in the humic substances extracted from clay $(<2 \mu \mathrm{m})$ and silt $(2-20 \mu \mathrm{m})$ fractions of soils at Wushwush, Ethiopia.

\begin{tabular}{|c|c|c|c|c|c|}
\hline \multirow[t]{2}{*}{ Land use } & \multirow[t]{2}{*}{ Aromatic- $\mathrm{C}^{\dagger}$} & Phenolic-C & Aliphatic-C & \multirow[t]{2}{*}{ Carboxylic-C } & \multirow[t]{2}{*}{ O-alkyl-C } \\
\hline & & & - $\%$ & & \\
\hline \multicolumn{6}{|c|}{ Clay } \\
\hline Natural forest & 16.0 & 12.8 & 10.7 & 36.3 & 24.2 \\
\hline Tea plantation & 16.0 & 12.5 & 10.1 & 37.9 & 23.5 \\
\hline Cultivation & 15.8 & 15.0 & 12.3 & 33.5 & 23.4 \\
\hline \multicolumn{6}{|c|}{$\underline{\text { Silt }}$} \\
\hline Natural forest & 8.1 & 5.2 & 5.9 & 46.5 & 34.3 \\
\hline Tea plantation & 7.7 & 7.6 & 5.0 & 41.0 & 38.7 \\
\hline Cultivation & 6.8 & 3.7 & 0.9 & 42.5 & 46.1 \\
\hline
\end{tabular}

$\dagger$ Aromatic- $\mathrm{C}=$ quinone type- $\mathrm{C}$ and protonated and alkylated aromatic- $\mathrm{C}+$ aromatic-C and possibly olefinic $\mathrm{C}$. 
Table 3. Relative proportions of organic C functional groups identified by C (1s) NEXAFS spectroscopy in the humic substances extracted from clay $(<2 \mu \mathrm{m})$ and silt $(2-20 \mu \mathrm{m})$ fractions of soils at Munesa, Ethiopia.

\begin{tabular}{|c|c|c|c|c|c|}
\hline Land use & Aromatic- $\mathrm{C} \dagger$ & Phenolic-C & Aliphatic-C & Carboxylic-C & O-alkyl-C \\
\hline \multicolumn{6}{|c|}{ Clay } \\
\hline Natural forest & 10.9 & 20.0 & 10.4 & 36.7 & 22.0 \\
\hline Cupressus plantation & 11.3 & 17.1 & 11.8 & 37.8 & 22.0 \\
\hline Cultivation & 14.9 & 10.1 & 10.2 & 37.0 & 27.8 \\
\hline \multicolumn{6}{|c|}{$\underline{\text { Silt }}$} \\
\hline Natural forest & 7.4 & 5.8 & 5.9 & 38.8 & 42.1 \\
\hline Cupressus plantation & 5.9 & 8.7 & 6.0 & 44.1 & 35.3 \\
\hline Cultivation & 30.2 & 7.0 & 5.4 & 33.0 & 24.4 \\
\hline
\end{tabular}

$\dagger$ Aromatic- $\mathrm{C}=$ quinone type- $\mathrm{C}$ and protonated and alkylated aromatic- $\mathrm{C}+$ aromatic- $\mathrm{C}$ and possibly olefinic $\mathrm{C}$.

the semi-quantitative analysis of the NEXAFS spectra, Scheinost et al. (2001) and Schäfer et al. (2003) compared the results of $\mathrm{C} \mathrm{K}$-edge NEXAFS with the results from ${ }^{13} \mathrm{C}$ NMR spectroscopy. These authors reported significant correlations between aromatic- $\mathrm{C}$, phenolic- $\mathrm{C}$, carboxylic-C, and O-alkyl-C groups identified by the two methods and concluded that $\mathrm{C}(1 \mathrm{~s})$ NEXAFS is a well suited method for characterization and quantification of organic $\mathrm{C}$ functional groups. They also suggested that it is a useful technique to detect systematic changes in the organic $\mathrm{C}$ functional groups in humic and fulvic acid that were extracted from the same soil type. We calculated correlation coefficients between the $\mathrm{C}$ functional groups identified by $\mathrm{C}(1 \mathrm{~s}) \mathrm{NEXAFS}$ and ${ }^{13} \mathrm{C}$ NMR spectroscopy (Solomon et al., 2002) from the humic substances under investigation. We found positive correlation $(P<0.05 ; n=12)$ between the aromatic-C $(r=0.64)$, phenolic-C $(r=0.74)$, carboxylic-C $(r=$ $0.62)$, and O-alkyl-C $(r=0.79)$ band areas identified by the C (1s) NEXAFS and ${ }^{13} \mathrm{C}$ NMR spectroscopy in the humic substances extracted from the clay and silt fractions of the soils under investigation. Although the relationship was weak, the proportions of aliphatic-C isolated by $\mathrm{C} \mathrm{K}$-edge NEXAFS were also positively correlated $(r=0.12)$ with the corresponding values of alkyl-C from ${ }^{13} \mathrm{C}$ NMR spectroscopy. The weak correlation between alkyl-C isolated by $\mathrm{C}$ K-edge NEXAFS and ${ }^{13} \mathrm{C}$ NMR spectroscopy might be explained by the weak character of the mixed valance/Rydberg-like transitions of aliphatic-C which results in lower C NEXAFS band intensities of these organic $\mathrm{C}$ structures as compared with the strong carboxylic-C $\pi^{*}$ transition (Cody et al., 1998; Scheinost et al., 2001). It may also be due to the slight overlap of band positions of these two $\mathrm{C}$ functional groups, which may lead to underestimation of the aliphatic- $\mathrm{C}$ and overestimation of the carboxylic-C structures by NEXAFS spectroscopy compared with the relatively larger amount of alkyl-C (16.1-26.2\%) measured by ${ }^{13} \mathrm{C}$ NMR spectroscopy from the humic substances under investigation (Solomon et al., 2002). However, with the exception of the slight overlap between the aliphatic- $\mathrm{C}$ and carboxylic- $\mathrm{C}$ moieties, the characteristic band positions were sufficiently separated to allow discrimination of organic $\mathrm{C}$ functional groups using the deconvolution method. Therefore, C K-edge XANES spectroscopy is a useful technique for detecting organic $\mathrm{C}$ functional groups and to follow their dynamics both qualitatively and semi-quantitatively in humic substances extracted from different soil types. Nevertheless, the results suggest the need for additional comparative studies involving a range of soil types from various agroecosystems and land-use practices.

\section{Organic Carbon Functional Groups Resolved by FTIR-ATR}

We investigated the structural composition of organic $\mathrm{C}$ and the changes in the composition of SOM induced by management practices in the humic substances extracted from clay and silt fractions of soils using synchrotron-based FTIR-ATR spectroscopy. The FTIR-ATR spectra of the clay and silt fractions (Fig. 4 and 5) showed a number of characteristic major absorbance peaks representing the molecular structure of humic substance extracts of the two size separates in the frequency range of 4000 to $800 \mathrm{~cm}^{-1}$. According to Fig. 4 and 5, the broad intense band at about $3374 \mathrm{~cm}^{-1}$ represents mainly the stretching vibrations of $\mathrm{H}$-bonded hydroxyl $(\mathrm{O}-\mathrm{H})$ groups of phenols with traces of amine $(\mathrm{N}-\mathrm{H})$ stretch (Chapman et al., 2001). The weak stretch vibration bands at about 2922 and $2851 \mathrm{~cm}^{-1}$ were due to vibrations of asymmetric and symmetric aliphatic $\left(\mathrm{CH}_{3}\right.$ and $\left.\mathrm{CH}_{2}\right)$ groups (Chen et al., 2002). The broad band near 1626 $\mathrm{cm}^{-1}$ was assigned primarily to aromatic- $\mathrm{C}(\mathrm{C}=\mathrm{C})$ vibrations and to a smaller extent to conjugated carbonyl- $\mathrm{C}$ $(\mathrm{C}=\mathrm{O})$ such as quinones, while the band around 1413 $\mathrm{cm}^{-1}$ may have originated from aliphatic $(\mathrm{C}-\mathrm{H})$ deformation of $\mathrm{CH}_{2}$ or $\mathrm{CH}_{3}$ groups (Stevenson, 1982). The band which appeared in the $1252 \mathrm{~cm}^{-1}$ region could arise from $\mathrm{C}-\mathrm{O}$ stretching and $\mathrm{OH}$ deformation of carboxylic $(\mathrm{COOH})$ groups. The strong band at about $1046 \mathrm{~cm}^{-1}$ could be attributed to $\mathrm{C}-\mathrm{O}$ stretching vibrations of polysaccharides (Stevenson, 1982; Haberhauer et al., 1998). The relative proportions of organic $\mathrm{C}$ functional groups calculated from peak intensities of the humic substances extracted from clay and silt fractions are summarized in Table 4 and 5. According to Fig. $4 \mathrm{a}$ and 5b, the clay spectra were characterized by the appearance of sharper and more intense peaks around 3374, 1626, and 1046 $\mathrm{cm}^{-1}$ regions indicating the presence of large proportions of H-bonded hydroxyl groups of phenols, aromatic-C, and polysaccharides- $\mathrm{C}$ in this size separate. These organic $\mathrm{C}$ functional groups represented on average $20.7,21.9$, and $19.3 \%$ of the total organic Cidentified 

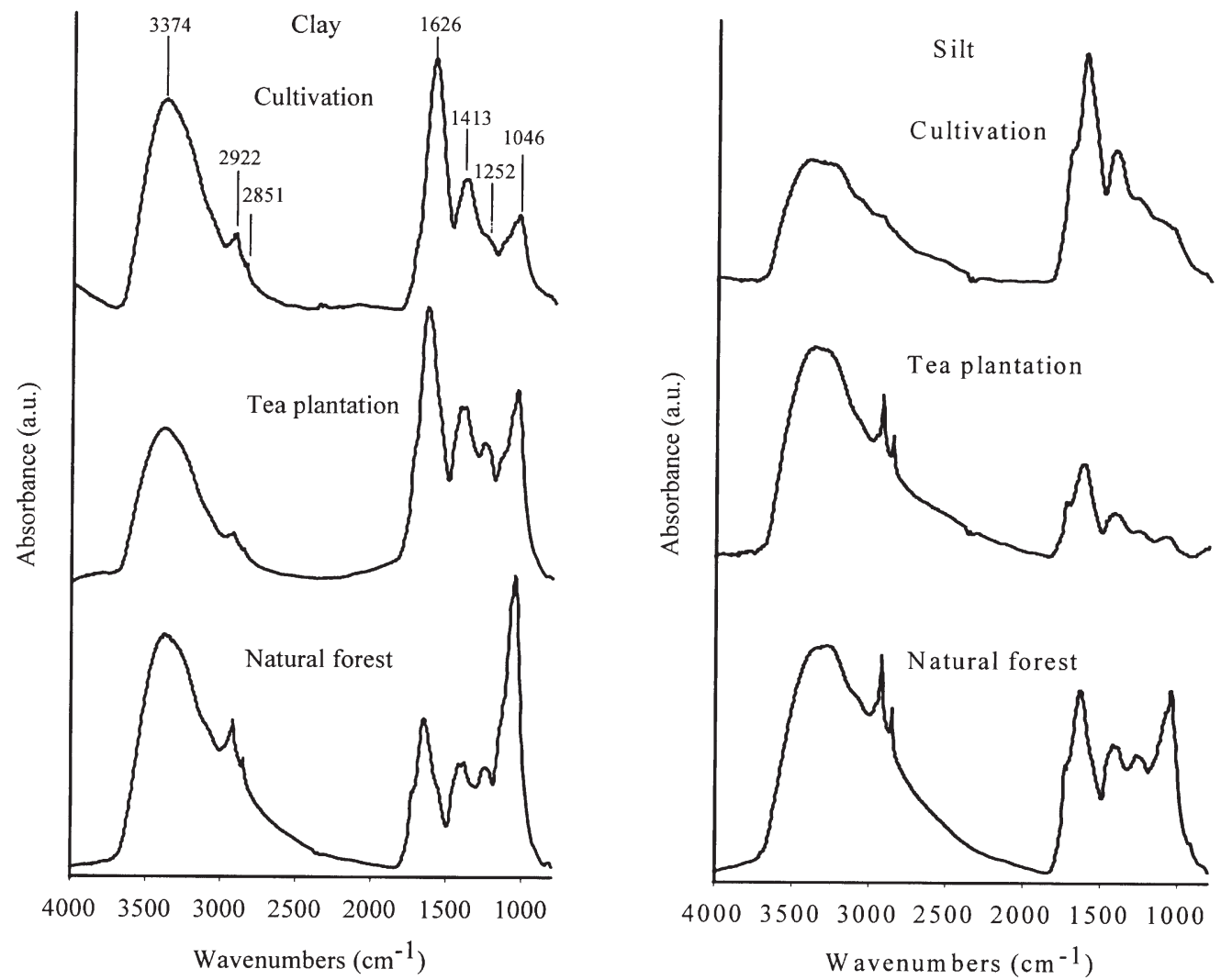

Fig. 4. Synchrotron-based FTIR-ATR spectra of humic substances extracted from the clay-and silt-size separates of soils from Wushwush, Ethiopia.
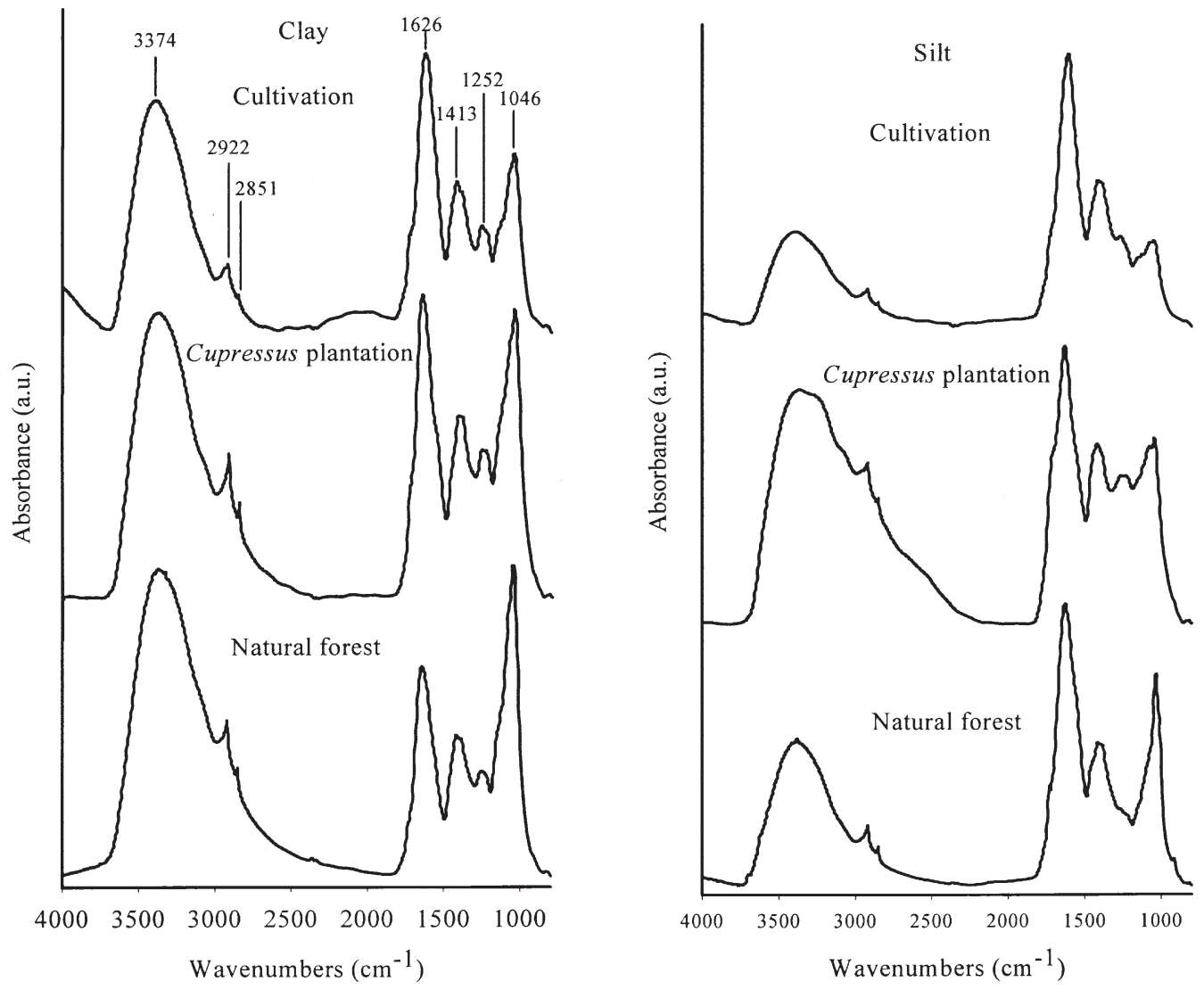

Fig. 5. Synchrotron-based FTIR-ATR spectra of humic substances extracted from the clay- and silt-size separates of soils from Munesa, Ethiopia. 
Table 4. Relative proportions of the various organic $\mathbf{C}$ functional groups resolved from the peak intensities of the FTIR-ATR spectra of the humic substances extracted from clay $(<2 \mu \mathrm{m})$ and silt $(2-20 \mu \mathrm{m})$ fractions of soils at Wushwush, Ethiopia.

\begin{tabular}{|c|c|c|c|c|c|c|c|c|}
\hline Land use & Phenol & Aliphatic $\dagger$ & Aromatic & Aliphatic $\nLeftarrow$ & Carboxylic & Polysaccharide & Aromaticity§ & Polysac-C/Arom-C\# \\
\hline \multicolumn{9}{|c|}{ Clay } \\
\hline Natural forest & 20.5 & 22.6 & 13.1 & 9.2 & 8.9 & 25.7 & 0.13 & 1.96 \\
\hline Tea plantation & $\mathbf{1 5 . 0}$ & 8.2 & 27.0 & 17.2 & 13.7 & 18.9 & 0.27 & 0.70 \\
\hline Cultivation & 23.9 & 13.7 & 28.7 & 14.9 & 8.0 & 10.8 & 0.29 & 0.38 \\
\hline \multicolumn{9}{|c|}{$\underline{\text { Silt }}$} \\
\hline Natural forest & 18.6 & 31.2 & 15.0 & 10.6 & 9.7 & 14.9 & 0.15 & 1.00 \\
\hline Tea plantation & 31.0 & 41.7 & 13.7 & 6.5 & 4.0 & 3.1 & 0.14 & 0.22 \\
\hline Cultivation & 21.4 & 4.9 & 40.0 & 23.2 & 6.3 & 4.2 & 0.40 & 0.10 \\
\hline
\end{tabular}

$\uparrow$ Aliphatic, weak stretch vibration of asymmetric and symmetric aliphatic $\left(\mathrm{CH}_{3}\right.$ and $\left.\mathrm{CH}_{2}\right)$ groups.

$\$$ Aliphatic, aliphatic (C-H) deformation of $\mathrm{CH}_{2}$ or $\mathrm{CH}_{3}$ groups.

$\S$ Aromaticity $=($ aromatic-C $) /($ Phenol-C + Aliphatic-C + Aromatic-C + Aliphatic-C + Aliphatic-C + Carboxylic-C + Polysaccharide-C $)$.

\# Polysac-C/Arom-C, (Polysaccharide-C/Aromatic-C).

by the FTIR-ATR spectroscopy in the humic substances extracted from the clay fraction, respectively (Table 4 and 5). Asymmetric and symmetric aliphatic-C groups accounted on average for $15.2 \%$ of SOM associated with the clay. The proportion of aliphatic-C deformation of $\mathrm{CH}_{2}$ or $\mathrm{CH}_{3}$ groups amounted for $13.1 \%$, whereas $\mathrm{C}-\mathrm{O}$ stretching and $\mathrm{OH}$ deformation of carboxylic $(\mathrm{COOH})$ groups comprised only $9.8 \%$. The spectral patterns and the proportions of the phenolic-C, aromatic-C, and polysaccharide- $\mathrm{C}$ moieties in the humic substance extracted from clay fraction were in reasonable agreement with the NEXAFS results from this size fraction. However, compared with the FTIR-ATR results, the proportion of carboxylic-C seems to be overestimated and the proportion of aliphatic-C underestimated by $\mathrm{C}$ K-edge spectroscopy. The FTIR-ATR spectra of the humic substances from silt fraction (Fig. $4 \mathrm{~b}$ and $5 \mathrm{~b}$ ) exhibited distinct differences in the composition of organic $\mathrm{C}$ functional groups compared with the spectral pattern of the clay fraction. They contained larger proportions of aromatic-C (25.5\%) as shown by a more pronounced absorption band at around $1626 \mathrm{~cm}^{-1}$. This was also indicated by the higher ratio of aromaticity (aromatic-C/phenolic- $\mathrm{C}+$ aliphatic- $\mathrm{C}+$ aromatic- $\mathrm{C}+$ aliphatic- $\mathrm{C}+$ carboxylic- $\mathrm{C}+$ polysaccharide- $\mathrm{C})$ in the silt (0.26) than in the clay (0.22) fraction (Table 4 and $5)$. In contrast to the clay, the silt fraction showed slightly larger proportions of asymmetric and symmetric aliphatic- $\mathrm{C}\left(\mathrm{CH}_{3}\right.$ and $\left.\mathrm{CH}_{2}\right)(19.7 \%)$ groups. However, both the peak intensities and the average proportions of the
C-O stretching vibrations of polysaccharides $(11.5 \%)$ were much smaller in the humic substances extracted from silt than from clay-size fractions. This was further demonstrated by the lower average value for the ratio of polysaccharide-C/aromatic-C (polysac-C/arom-C) in the humic substances extracted from silt $(0.51)$ fraction compared with the humic substances extracted from clay (1.02) fraction (Table 4 and 5). These results clearly indicate that the SOM associated with the silt fraction was more aromatic compared with the SOM associated with the clay fraction, while the humic substances extracted from the silt contain lower amount of carbohydrates than the ones extracted from the clay. They also supports our previous study on these soils using ${ }^{13} \mathrm{C}$ NMR spectroscopy and wet-chemical analysis, where we found lower aromaticity and larger enrichment of carbohydrates (especially microbial-derived sugars such as galactose, mannose, fucose, and rhamnose) in SOM associated with the clay than with the silt fraction (Solomon et al., 2002). Loss of O-alkyl C structures and an increased accumulation of aromatic-C (probably from lignin and tannins) in silt compared with clay have been also observed by Schmidt et al. (2000b). The fact that potentially labile polysaccharides accumulate in the clay fraction could be attributed to the higher production of microbial metabolites and their intimate association and stabilization against mineralization in clay minerals (Oades et al., 1987; Guggenberger et al., 1994; Solomon et al., 2000). Schmidt and Kögel-Knabner (2002) suggested that sorptive organo-mineral interactions with

Table 5. Relative proportions of the various organic $\mathbf{C}$ functional groups resolved from the peak intensities of the FTIR-ATR spectra of the humic substances extracted from clay $(<2 \mu \mathrm{m})$ and silt $(2-20 \mu \mathrm{m})$ fractions of soils at Munesa, Ethiopia.

\begin{tabular}{|c|c|c|c|c|c|c|c|c|}
\hline Land use & Phenol & Aliphatic $\dagger$ & Aromatic & Aliphatic & Carboxylic & Polysaccharide & Aromaticity§ & Polysac-C/Arom-C\# \\
\hline \multicolumn{9}{|c|}{ Clay } \\
\hline Natural forest & 22.9 & 19.6 & 15.6 & 10.5 & 7.9 & 23.5 & 0.16 & 1.50 \\
\hline Cupressus plantation & 19.7 & 16.6 & 20.9 & 12.6 & 10.3 & 19.9 & 0.21 & 0.95 \\
\hline $\begin{array}{l}\text { Cultivation } \\
\end{array}$ & 22.0 & 10.2 & 26.4 & 14.3 & 10.2 & 16.9 & 0.26 & 0.64 \\
\hline \multicolumn{9}{|c|}{$\underline{\text { Silt }}$} \\
\hline Natural forest & 15.4 & 10.6 & 29.5 & 15.0 & 7.4 & 22.1 & 0.29 & 0.75 \\
\hline Cupressus plantation & 17.9 & 21.9 & 21.1 & 13.7 & 11.3 & 14.1 & 0.21 & 0.67 \\
\hline Cultivation & 18.1 & 8.0 & 33.8 & 18.2 & 11.2 & 10.7 & 0.34 & 0.32 \\
\hline
\end{tabular}

$\dagger$ Aliphatic, weak stretch vibration of asymmetric and symmetric aliphatic $\left(\mathrm{CH}_{3}\right.$ and $\left.\mathrm{CH}_{2}\right)$ groups.

Aliphatic, aliphatic $(\mathrm{C}-\mathrm{H})$ deformation of $\mathrm{CH}_{2}$ or $\mathrm{CH}_{3}$ groups.

$\S$ Aromaticity $=($ aromatic-C $) /($ Phenol-C + Aliphatic-C + Aromatic-C + Aliphatic-C + Aliphatic-C + Carboxylic-C + Polysaccharide-C $)$.

\# Polysac-C/Arom-C, (Polysaccharide-C/Aromatic-C). 
clay size minerals with large surface areas could protect polysaccharides from degradation and may lead to their accumulation in clay fraction. The average proportions of H-bonded hydroxyl $(\mathrm{O}-\mathrm{H})$ groups of phenols $(\mathrm{O}-\mathrm{H})$ $(20.4 \%)$, aliphatic $(\mathrm{C}-\mathrm{H})$ deformation of $\mathrm{CH}_{2}$ or $\mathrm{CH}_{3}$ $(14.5 \%)$, and $\mathrm{C}-\mathrm{O}$ stretching and $\mathrm{O}-\mathrm{H}$ deformation of carboxylic $(\mathrm{COOH})(8.3 \%)$ groups were of similar magnitude in the two size fractions.

The FTIR-ATR spectra (Fig. 4 and 5) and the relative proportions of the signal intensities (Table 4 and 5) also clearly demonstrated the long-term impact of landuse on the different organic $\mathrm{C}$ functional forms present in the size separates of these tropical soils. The most striking changes in the signal intensities of FTIR-ATR spectra of the humic substances extracts of particlesize fractions under different land-use systems appeared near 1046 and $1626 \mathrm{~cm}^{-1}$ regions, which represent $\mathrm{C}-\mathrm{O}$ stretching vibrations of polysaccharides and aromatic $\mathrm{C}$ $(\mathrm{C}=\mathrm{C})$, respectively (Fig. 4 and 5). The FTIR-ATR spectra of humic substances from the natural forests were distinguished from the plantations and cultivated soils by more intense $\mathrm{C}-\mathrm{O}$ stretching vibrations of the polysaccharide region. According to Table 4 and 5, this signal intensity expressed as the relative proportions of $\mathrm{C}-\mathrm{O}$ stretching vibrations of polysaccharides decreased in the order: natural forests $>$ plantations $>$ cultivated fields both in the clay and silt fractions at the Wushwush and Munesa sites. The decrease in signal intensities and relative proportions following land-use changes reflected an enrichment of carbohydrates in the humic substances extracted from the size separates under natural forests compared with the corresponding size separates under long-term plantation and continuous cultivation. The lower carbohydrate concentrations in the arable soils may be attributed to the lower biomass input coupled with the rapid depletion of polysaccharides due to accelerated mineralization of the original SOM following clear-cutting and long-term continuous cultivation under the subhumid tropical highland environment. These results are in agreement with our previous study on these soils using degradative wet-chemical analysis and ${ }^{13} \mathrm{C}$ NMR spectroscopy, where we found lower concentrations of non-cellulosic carbohydrates in SOM associated with the size separates of the plantations and continuously cultivated soils compared with the corresponding size separates of the natural forests (Solomon et al., 2002). In contrast, the absorption band intensity and the relative proportion of aromatic- $\mathrm{C}(\mathrm{C}=\mathrm{C})$ vibrations increased in the order: natural forest $<$ plantation $<$ cultivation at both sites, indicating that more recalcitrant aromatic forms are becoming the dominant forms of organic $\mathrm{C}$ functional groups in the humic substances extracted from the plantation and cultivated soils following land-use changes. The above results were also supported by the polysac-C/arom-C ratios and by the degree of aromaticity of the humic substances (Table 4 and 5). According to Table 4 and 5, the ratio of polysac-C/arom-C decreased considerably after clearcutting and subsequent establishment of plantations or cultivated fields both in the humic substances extracted clay (from 1.96 and 1.50 to 0.38 and 0.64 ) and silt (from
1.00 and 0.75 to 0.10 and 0.32 ) fractions of the soils at the Wushwush and Munesa sites, respectively. However, the degree of aromaticity in the humic substances increased from 0.13 and 0.16 to 0.29 and 0.26 in the clay fraction and from 0.15 and 0.29 to 0.40 and 0.34 in silt fraction due to agricultural management at the two sites, respectively. Our results concur positively with the results of Golchin et al. (1995) and Baldock et al. (1997) who suggested that tillage of native soils can cause loss of more readily decomposable fractions, potentially leading to an increase in the proportions of the more recalcitrant aromatic $\mathrm{C}$ forms in the SOM at the advanced stage of decomposition. They also compared positively with the statistical analysis of published ${ }^{13} \mathrm{C}$ NMR data by Mahieu et al. (1999), which showed that humic acids from cultivated soils have higher concentration of aromatic $\mathrm{C}$ than humic acids from non-cultivated soils.

The FTIR-ATR spectral features and the peak intensity values also indicated accumulation of some aliphatic structures in the humic substances extracted from the size separates of soils from the natural forests and plantations than the cultivated fields. This was shown by the intensities of the peaks produced by vibrations of asymmetric and symmetric aliphatic $\left(\mathrm{CH}_{3}\right.$ and $\left.\mathrm{CH}_{2}\right)$ groups (Fig. 4 and 5 and Table 4 and 5). These findings are in general agreement with previous investigations on the fate of organic $\mathrm{C}$ moieties during composting of organic matter (Inbar et al., 1989) or humification of SOM in forest-derived soils (Kögel-Knabner, 1993; Haberhauer et al., 1998), where a decrease of aliphatic chains following decomposition of organic matter was observed. However, the decrease in the signal intensities of the asymmetric and symmetric aliphatic groups was not complimented by the trend of aliphatic $(\mathrm{C}-\mathrm{H})$ deformation of $\mathrm{CH}_{2}$ or $\mathrm{CH}_{3}$ groups, which showed a small but consistent increase in the peak intensities in the humic substances extracted from the cultivated soils. In comparison, the changes in the relative proportions of $\mathrm{C}-\mathrm{O}$ stretching and $\mathrm{OH}$ deformation of carboxylic $(\mathrm{COOH})$ groups and $\mathrm{H}$-bonded hydroxyl $(\mathrm{O}-\mathrm{H})$ groups of phenols in the humic substance extracts following land-use changes were small and inconsistent at both sites.

Haberhauer et al. (2000) and Pérez et al. (2004) suggested that although FTIR spectroscopy can be used for identification of functional groups and determination of their relative distribution, it does not provide detailed information about chemical or structural changes in humic acids in studies involving short-term conversions of forest to cultivated land or pastures. On the contrary, the changes in ratios, proportions and peak intensities of the FTIR-ATR spectral patterns observed in the present investigation clearly indicate that easily degradable SOM constituents such as polysaccharide- $\mathrm{C}$ and some aliphatic-C moieties were oxidized due to accelerated mineralization following land clearing and long-term cultivation. The remaining organic matter in the humic substances extracted from the size separates of the agriculturally managed soils was dominated by recalcitrant aromatic- $\mathrm{C}$ structures, clearly indicating a change in the 
composition and structural stability of the SOM following long-term land use changes. Hence, it is possible to suggest that synchrotron-based FTIR-ATR spectroscopy is a powerful, non-evasive technique that has potential to obtain detailed information on the complex structural characteristics of organic macromolecules, determine their relative distribution and effectively follow the changes brought by long-term land-use changes on the composition of novel SOM.

\section{CONCLUSIONS}

With the help of C (1s) NEXAFS spectroscopy, we were able to effectively identify and fingerprint the various functional groups representing molecular structure of organic $\mathrm{C}$ from the fine scale details of the absorption spectra that occur at the $\mathrm{C} \mathrm{K}$-edge in the humic substances extracted from the clay and silt fractions of soils. Besides, we were able to investigate the distribution and impact of land-use changes on the amount and composition of organic $\mathrm{C}$ moieties in humic substances extracted from these sizes separates qualitatively and semi-quantitatively.

The NEXAFS spectra showed that carboxylic-C and $\mathrm{O}$-alkyl-C functional groups were the dominant forms of organic $\mathrm{C}$, followed by moderate amounts of aromatic- $\mathrm{C}$ and phenolic- $\mathrm{C}$ groups. The aliphatic- $\mathrm{C}$ forms contributed only to a small portion of the total SOM associated with the humic substances extracted from the two size fractions. Carbon K-edge NEXAFS spectroscopy, for the most part exhibited good selectivity, where specific energy regions tended to correspond to the $\mathrm{C}$ in discrete organic functional groups. However, regions of slight overlap between the bands associated especially with $1 \mathrm{~s}-3 \mathrm{p} / \sigma^{*}$ transition of aliphatic- $\mathrm{C}$ and $1 \mathrm{~s}-\pi^{*}$ transition of carboxylic-C may not be excluded. The NEXAFS spectral features did not reveal clear and consistent differences in relative abundance of the various organic $\mathrm{C}$ functional groups in the humic substance extracts of the size fractions under the different land-use systems.

Synchrotron-based FTIR-ATR spectroscopy, however, clearly demonstrated the long-term impact of landuse changes on the amount, composition, and structural stability of the different organic $\mathrm{C}$ functional forms present in the humic substances extracted from the size separates. Easily degradable SOM constituents such as polysaccharide- $\mathrm{C}$ and some labile components of aliphatic- $\mathrm{C}$ moieties were more prominent in the humic substance extracted from the size fractions of native forest soils, while aromatic- $\mathrm{C}$ and some recalcitrant forms of aliphatic-C forms dominated the SOM associate with the humic substances extracted from the size separates of soils from the plantations and continuously cultivated fields.

Therefore, C K-edge NEXAFS and synchrotron-based FTIR-ATR spectroscopy are powerful, nondestructive techniques that can potentially be used not only to identify and fingerprint the complex structural characteristics of organic $\mathrm{C}$ macromolecules but also to determine the impact of long-term anthropogenic management on the composition and biogeochemical cycling of organic $\mathrm{C}$ in terrestrial ecosystems.

\section{ACKNOWLEDGMENTS}

We thank Drs. S. Wirick, C. Jacobsen, L. Miller, and N.S. Marinkovic for invaluable material support and assistance with the spectroscopic analyses. The C (1s) NEXAFS data under the project No. 4988 was collected using the X-1A1 STXM developed by the group of J. Kirz and C. Jacobsen at SUNY Stony Brook with support from the Office of Biological and Environmental Research, U.S. Department of Energy under contract DE-FG02-89ER60858, and the NSF under grant DBI-9605045. The zone plates were developed by S. Spector and C. Jacobsen of Stony Brook and D. Tennant of Lucent Technologies Bell Labs, with support from the NSF under grant ECS-9510499. The FTIR-ATR data under the project No. 4837 was collected at U10B beamline of the National Synchrotron Light Source (NSLS), Brookhaven National Laboratory. The U10B beamline is supported by the U.S. Department of Energy under the contract No. DEAC02-98CH10886.

\section{REFERENCES}

Avery, B.W., and C.L. Bascomb. 1974. Soil survey laboratory methods. p. 19-25. In Tech. Monogr., No. 6. Rothamsted Exp. Stn., Harpenden, UK.

Baldock, J.A., J.M. Oades, P.N. Nelson, T.M. Skene, A. Golchin, and P. Clarke. 1997. Assessing the extent of decomposition of natural organic materials using solid-state ${ }^{13} \mathrm{C}$ NMR spectroscopy. Aust. J. Soil Res. 35:1061-1083.

Blume, H.P., and U. Schwertmann. 1969. Genetic evaluation of profile distribution of aluminum, iron, and manganese oxides. Soil Sci. Soc. Am. J. 33:438-444.

Boese, J., A. Osanna, C. Jacobsen, and J. Kirz. 1997. Carbon edge XANES spectroscopy of amino acids and peptides. J. Electron Spectrosc. Relat. Phenom. 85:9-15.

Boyce, C.K., G.D. Cody, M. Feser, C. Jacobsen, A.H. Knoll, and S. Wirick. 2002. Organic chemical differentiation within fossil plant cell walls detected with X-ray spectroscopy. Geol. Soc. Am. 30:1039-1042.

Capriel, P., P. Härter, and D. Stephenson. 1992. Influence of management on the organic matter of a mineral soil. Soil Sci. 153:122-128.

Chapman, S.J., C.D. Campbell, A.R. Fraser, and G. Puri. 2001. FTIR spectroscopy of peat in and bordering Scots pine woodland: Relationship with chemical and biological properties. Soil Biol. Biochem. 33:1193-1200.

Chefetz, B., M.J. Salloum, A.P. Deshmukh, and P.G. Hatcher. 2002. Structural components of humic acids as determined by chemical modifications and carbon-13 NMR, pyrolysis-, and thermochemolysis-gas chromatography/mass spectrometry. Soil Sci. Soc. Am. J. 66:1159-1171.

Chen, J., B. Gu, E.J. LeBoeuf, H. Pan, and S. Dai. 2002. Spectroscopic characterization of the structural and functional properties of natural organic matter fractions. Chemosphere 48:59-68.

Cody, G.D., and R.E. Botto. 1995. Inner-shell spectroscopy and imaging of a subbituminous coal: In-situ analysis of organic and inorganic microstructure using $\mathrm{C}(1 \mathrm{~s})-, \mathrm{Ca}(2 \mathrm{p})-$, and $\mathrm{C} 1(2 \mathrm{~s})-\mathrm{NEXAF}$. Energy Fuels 9:525-533.

Cody, G.D., R.E. Botto, H. Ade, S. Behal, M. Disko, and S. Wirick. 1995. Inner-shell spectroscopy and imaging of a subbituminous coal: In-situ analysis of organic and inorganic microstructure using $\mathrm{C}(1 \mathrm{~s})-\mathrm{Ca}(2 \mathrm{p})-$, and $\mathrm{Cl}(2 \mathrm{~s})-\mathrm{NEXAFS}$. Energy Fuels 9:525-533.

Cody, G.D., H. Ade, S. Wirick, G.D. Mitchell, and A. Davis. 1998. Determination of chemical-structural changes in vitrinite accompanying luminescence alteration using C-NEXAFS analysis. Org. Geochem. 28:441-455.

del Rio, J.C., D.E. McKinney, H. Knicker, M.A. Nanny, R.D. Minard, and P.G. Hatcher. 1998. Structural characterization of bio- and 
geo-macromolecules by off-line thermochemolysis with tetramethylammonium hydroxide. J. Chrom. 823:433-448.

Eglinton, T.I., L.I. Aluwihari, J.E. Bauer, E.R.M. Druffel, and A.P. McNichol. 1996. Gas chromatographic isolation of individual compounds from complex matrices for radiocarbon dating. Anal. Chem. 68:904-912.

Golchin, A., P. Clarke, J.M. Oades, and J.O. Skjemstad. 1995. The effects of cultivation on the composition of organic matter and structural stability of soils. Aust. J. Soil Res. 33:975-993.

Gressel, N., Y. Inbar, A. Singer, and Y. Chen. 1995. Chemical and spectroscopic properties of leaf litter and decomposed organic matter in the Carmel range, Israel. Soil Biol. Biochem. 27:23-31.

Guggenberger, G., W. Zech, L. Haumaier, and B.T. Christensen. 1994. Land-use effects on the composition of organic matter in particlesize separates of soils: II. CPMAS and solution ${ }^{13} \mathrm{C}$ NMR analysis. Eur. J. Soil Sci. 46:147-158.

Guggenberger, G., and W. Zech. 1999. Soil organic matter composition under primary forest, pasture and secondary forest succession, Región Huetar Norte, Costa Rica. For. Ecol. Manage. 124:93-104.

Gutiérrez-Sosa, A., J.F. Walsh, R. Lindsay, P.L. Wincott, and G. Thornton. 1999. Carbonate co-adsorption geometry on $\mathrm{TiO}_{2}(110)$ 1×1-Na. Surface Sci. 433-435:538-542.

Haberhauer, G., B. Rafferty, F. Strebl, and M.H. Gerzabek. 1998. Comparison of the composition of forest soil litter derived from three different sites at various decompositional stages using FTIRspectroscopy. Geoderma 83:331-342.

Haberhauer, G., B. Feigl, M.H. Gerzabeck, and C. Cerri. 2000. FT-IR spectroscopy of organic matter in tropical soils: Changes induced through deforestation. Appl. Spectrosc. 54:221-224.

Inbar, Y., Y. Chen, and Y. Hadar. 1989. Solid-state carbon-13 nuclear magnetic resonance and infrared spectroscopy of composted organic matter. Soil Sci. Soc. Am. J. 53:1695-1701.

IPCC. 2001. Climate Change 2001: The scientific basis. Available online at: http://www.grida.no/climate/ipcc_tar/wg1/index.htm (verified 24 Aug. 2004) IPCC, UNEP, WMO, Geneva, Switzerland.

Jablonski, E.L., J.L. Lenhart, S. Sambasivan, D.A. Fischer, R.L. Jones, E.K. Lin, W. Wu, D.L. Goldfarb, K. Temple, M. Angelopoulos, and H. Ito. 2003. NEXAFS measurements of the surface chemistry of chemically amplified photoresists. Am. Inst. Phys. Conf. Proc. 683:439-443.

Jokic, A., J.N. Cutler, E. Ponomarenko, G. van der Kamp, and D.W. Anderson. 2003. Organic carbon and sulfur compounds in wetland soils: Insights on structure and transformation processes using K-edge XANES and NMR spectroscopy. Geochim. Cosmochim. Acta 67:2585-2597.

Kögel-Knabner, I. 1993. Biodegradation and humification processes in forest soils. Soil Biochem. 8:101-135.

Kögel-Knabner, I. 1995. Composition of soil organic matter. p. 66-78. In P. Nannipieri and K. Alef (ed.) Methods in applied soil microbiology and biochemistry. Academic Press, London.

Kögel-Knabner, I. 1997. ${ }^{13} \mathrm{C}$ and ${ }^{15} \mathrm{~N}-\mathrm{NMR}$ spectroscopy as a tool in soil organic matter studies. Geoderma 80:243-270.

Kögel-Knabner, I. 2000. Analytical approaches for characterizing soil organic matter. Org. Geochem. 31:609-625.

Lal, R. 2001. World cropland soils as a source or sink for atmospheric carbon. Adv. Agron. 71:145-191.

Leinweber, P., and H.R. Schulten. 1998. Advances in analytical pyrolysis of soil organic matter. J. Anal. Appl. Pyrolysis 47:165-189.

Lobo, R.P.S.M., J.D. LaVeigne, D.H. Reitze, D.B. Tanner, and G.L. Carr. 2002. Subnanosecond, time-resolved, broadband infrared spectroscopy using synchrotron radiation. Rev. Sci. Instrum. 73: $1-10$.

Macko, S.A., M. Ryan, and M.H. Engel. 1998. Stable isotopic analysis of individual carbohydrates by gas chromatographic/combustion/ isotope ratio mass spectrometry. Chem. Geol. 152:205-210.

Mahieu, N., D.S. Powlson, and E.W. Randall. 1999. Statistical analysis of the published carbon-13 CPMAS NMR spectra of soil organic matter. Soil Sci. Soc. Am. J. 63:307-319.

Martin, M.C., and W.R. McKinney. 1998. The first synchrotron infrared beamlines at the advanced light source: Micro-spectroscopy and fast timing. Proceed. Mater. Res. Soc. 524:1-11.

McHardy, W.J., and L. Robertson. 1983. An optical scanning electron microscopic and microanalytical study of cementation in some podzols. Geoderma 30:161-170.

McKeague, J.A., and C. Wang. 1980. Micromorphology and energy dispersive analysis of ortstein horizons of podzolic soils from New Brunswick and Nova Scotia, Canada. Can. J. Soil Sci. 60:9-21.

Mehra, O.P., and M.L. Jackson. 1960. Iron oxide removal from soils and clays by a dithionite-citrate system buffered with sodium bicarbonate. Clays Clay Miner. 7:317-327.

Neuhäusler, U., S. Abend, G. Lagaly, and C. Jacobsen. 1999. Soft $\mathrm{x}$-ray spectromicroscopy on solid stabilized emulsions. Coll. Polym. Sci. 277:719-726.

Oades, J.M., A.M. Vassallo, A.G. Waters, and M.A. Wilson. 1987. Characterization of organic matter in particle size and density fractions from a red-brown earth by solid state 13 CNMR. Aust. J. Soil Res. 25: 71-82.

Pérez, M.G., L. Martin-Netoa, S.C. Saab, E.H. Novotny, D.M.B.P Miloria, V.S. Bagnatod, L.A. Colnagoa, W.J. Meloe, and H. Knickerf. 2004. Characterization of humic acids from a Brazilian Oxisol under different tillage systems by EPR, ${ }^{13} \mathrm{C}$ NMR, FTIR and fluorescence spectroscopy. Geoderma 118:181-190.

Rothe, J., M.A. Denecke, and K. Dardenne. 2000. Soft x-ray spectromicroscopy investigation of the interaction of aquatic humic acid and clay colloids. J. Coll. Interface Sci. 231:91-97.

Saiz-Jimenez, C. 1994. Analytical pyrolysis of humic substances: Pitfalls, limitations and possible solutions. Environ. Sci. Technol. 28:1773-1780.

Schäfer, T., N. Hertkorn, R. Artinger, F. Claret, and A. Bauer. 2003. Functional group analysis of natural organic colloids and clay association kinetics using C(1s) spectromicroscopy. J. Phys. France. 104:409-412.

Scheinost, A.C., R. Kretzschmar, I. Christl, and C. Jacobsen. 2001. Carbon group chemistry of humic and fulvic acid: A comparison of C-1s NEXAFS and ${ }^{13} \mathrm{C}-\mathrm{NMR}$ spectroscopies. p. 39-47. In E.A. Ghabbour and G. Davies (ed.) Humic substances: Structures, models and functions. Royal Soc. Chem., Gateshead, UK.

Schmidt, C., J. Thieme, U. Neuhausler, U. Schulte-Ebbert, G. AbbtBraun, C. Specht, C. Jacobsen. 2000a. Association of particles and structures in the presence of organic matter. Am. Inst. Phys. Conf. Proc. 507:313-318.

Schmidt, M.W.I., H. Knicker, and I. Kögel-Knabner. 2000b. Organic matter accumulating in Aeh and Bh horizons of a Podzol-chemical characterization in primary organo-mineral associations. Org. Geochem. 31:727-734.

Schmidt, M.W.I., and I. Kögel-Knabner. 2002. Organic matter in particle-size fractions from A and B horizons of a Haplic Alisol. Eur. J. Soil Sci. 53:383-391.

Schnitzer, M., and S.U. Khan. 1972. Humic substances in the environment. Marcel Dekker Inc., New York.

Skjemstad, O.J., R.C. Dalal, and P.F. Barron. 1986. Spectroscopic investigations of cultivation effects on organic matter of Vertisols. Soil Sci. Soc. Am. J. 50:354-359.

Soil Survey Staff. 1999. Keys to soil taxonomy. 8th ed. Pocahontas Press, Blacksburg, VA.

Solomon, D., J. Lehmann, and W. Zech. 2000. Land use effects on soil organic matter properties of chromic Luvisols in the semiarid tropics: Carbon, nitrogen, lignin and carbohydrates. Agric. Ecosyst. Environ. 78:203-213.

Solomon, D., F. Fritzsche, M. Tekalign, J. Lehmann, and W. Zech. 2002. Soil organic matter composition in the sub-humid Ethiopian highlands as influenced by deforestation and agricultural management. Soil Sci. Soc. Am. J. 66:68-82.

Solomon, D., J. Lehmann, and C.E. Martinez. 2003. Sulfur K-edge XANES spectroscopy as a tool for understanding sulfur dynamics in soil organic matter. Soil Sci. Soc. Am. J. 67:1721-1731.

Stevenson, F.J., and K.M. Goh. 1971. Infrared spectra of humic acids and related substances. Geochim. Cosmochim. Acta 35:471-483.

Stevenson, F.J. 1982. Humus. Chemistry: Genesis, composition, reactions. John Wiley \& Sons Inc., New York.

Stöhr, J. 1992. NEXAFS spectroscopy. Springer series in surface sciences. Vol. 25. Springer, Berlin.

Tanaka, T., S. Nagao, and H. Ogawa. 2001. Attenuated total reflection 
fourier transform infrared (ATR-FTIR) spectroscopy of functional groups of humic acid dissolving in aqueous solution. Anal. Sci. 17:1081-1084.

Wilding, L.G. 1985. Spatial variability: Its documentation, accommodation and implication to soil survey. p. 166-187. In D.R. Nielsen and J. Bouma (ed.) Soil spatial variability. PUDOC, Wageningen, The Netherlands.
Yuan, G., M. Soma, H. Seyama, B.K.G. Theng, L.M. Lavkulich, and T. Takamatsu. 1998. Assessing the surface composition of soil particles from some Podzolic soils by X-ray photoelectron spectroscopy. Geoderma 86:169-181.

Zhang, X., and W. Amelung. 1996. Gas chromatographic determination of muramic acid, glucosamine, galactosamine and mannosamine in soils. Soil Biol. Biochem. 28:1201-1206. 